\title{
Are for-profit hospital conversions harmful to patients and to Medicare?
}

\author{
Gabriel Picone* \\ Shin-Yi Chou ${ }^{* *}$ \\ and \\ Frank Sloan $^{* * *}$
}

We examine how changes in hospital ownership to and from for-profit status affect quality and Medicare payments per hospital stay. We hypothesize that hospitals converting to for-profit ownership boost postacquisition profitability by reducing dimensions of quality not readily observed by patients and by raising prices. We find that 1-2 years after conversion to for-profit status, mortality of patients, which is difficult for outsiders to monitor, increases while hospital profitability rises markedly and staffing decreases. Thereafter, the decline in quality is much lower. A similar decline in quality is not observed after hospitals switch from for-profit to government or private nonprofit status.

\section{Introduction}

- There is ongoing debate about the effect of ownership on hospital performance. A profit incentive may improve efficiency and, perhaps, observable quality (Hansmann, 1996). However, profit-seeking may also encourage management to exploit market power, either by raising price or lowering quality in ways not observable by consumers. Such exploitation is more likely in markets, such as hospital markets, in which consumers lack information (Arrow, 1963; Weisbrod, 1988; Hart, Shleifer, and Vishny, 1997). Concerns about the latter have led state attorneys general and other policy makers to scrutinize changes in hospital ownership in recent years, especially those to for-profit status (Hyman, 1998). The vast majority of studies of effects of hospital ownership on performance have focused on differences among hospitals with various ownership forms. With several notable exceptions (e.g., Gowrisankaran and Town, 1999; McClellan and Staiger, 2000; Silverman and Skinner, 2001; Taylor, Whellan, and Sloan, 1999), most of these studies

*University of South Florida; gpicone@ coba.usf.edu.

** New Jersey Institute of Technology and NBER; chou@adm.njit.edu.

${ }^{* * *}$ Duke University and NBER; fsloan@hpolicy.duke.edu.

Research for this study was supported in part by grants to Duke University from the National Institute on Aging (Grant No. 2RO1-AG-09468-04A1) and the Robert Wood Johnson Foundation, the latter, a grant administered by the Academy for Health Services Research and Health Policy entitled Hospital Ownership Conversions. We wish to thank David Cutler, William Dow, Bradley Kamp, Elizabeth Richardson Vigdor, participants in the Triangle Health Economics Workshop (at the University of North Carolina, Chapel Hill, September 2000, and two anonymous referees for helpful comments. 
have shown hospital ownership to have little or no effect on relevant indicators of performance (Marsteller, Bovbjerg, and Nichols, 1998; Sloan, 2000). But they have not directly tested whether or not a conversion from a nonprofit-seeking to a profit-seeking organization truly changes such important attributes of hospital behavior as quality of care.

Analysis of conversions is likely to be fruitful for two reasons. First, by limiting the analysis to changes in ownership status, we hold other pertinent characteristics, such as hospital location, constant. This permits a much more precise identification of the effects of ownership. For-profit hospital performance is attributable, at least in part, to where for-profit facilities locate (Norton and Staiger, 1994). Within such local markets, for-profit hospitals may supply similar quality of care and levels of public goods as do hospitals organized under other forms of ownership (McClellan and Staiger, 2000; Norton and Staiger, 1994). Second, from a policy perspective, this is the change that attorneys general and other policymakers are asked to make decisions about. Although there is some public oversight over hospital ownership conversions, state statutes barring for-profit hospital entry are very rare.

In this article we analyze effects of changes in hospital ownership from government or private nonprofit status to for-profit status and the reverse on two outcomes, survival and Medicare payments per hospital stay. Survival is arguably the most important and certainly the leastambiguously measured indicator of hospital quality. To the extent that converting hospitals lower quality, this should be reflected in survival, especially among relatively vulnerable populations such as the elderly. Also, mortality at several weeks or months following discharge from the hospital is difficult for outsiders to monitor. Medicare payments per stay are important, since for-profit hospitals may be more adept in maximizing revenue from this public program.

Hospitals do not change ownership in a vacuum. From available literature, as summarized by Sloan (2002), we know that many hospitals experience financial distress before the conversion, reflecting in part a drop in demand for inpatient care and increased competition from other hospitals in their markets. A change in ownership is often sought to enable the hospital to better cope with the changes in product market conditions. Some converting hospitals seek better access to equity capital, again because they perceive that other sources of capital are more costly, recognizing at the same time that converting to for-profit status may reduce private and certainly public subsidies in the form of removal of tax exemptions. Some public hospitals convert to other ownership forms to relax constraints on employment and to expand the market areas in which they operate.

Hospitals experiencing a drop in quality may be more likely to convert. If quality is judged to be poor after conversion, this may be a result of a trend toward reduced quality that preceded the conversion rather than a result of the conversion itself. Reductions in quality prior to conversion have not been documented in previous studies, but neither do such studies rule this out.

Also, choice of hospital by individuals is plausibly jointly determined with expected outcomes. Although we used a database rich in patient characteristics, measured both at the time of admission and at an interview administered before the admission, the patient and/or the patient's physician were likely to have known much more than the researcher about the severity of his/her illness and, to some extent, the expected outcomes in alternative hospitals, which are also likely to be heterogeneous. If more severely ill patients obtain care at hospitals offering higher quality of care, it will be important to account for this in our empirical analysis. Another source of endogeneity is unobserved patient preferences, such as those relating to proximity to the hospital versus hospital quality.

Although for-profit conversions have received much more publicity, conversions in the other direction have been almost as frequent (Desai, Young, and Lukas, 1998; Needleman, Chollet, and Lamphere, 1997). By assessing effects in both directions, we were better able to isolate effects of changes in ownership from effects of change in hospital organization per se. With a panel over a considerable time period, 1984-1995, we were able to implement a difference-in-difference approach designed to mitigate potential selection biases.

Section 2 provides a conceptual framework for our study. In Section 3 we describe our data, and in Section 4 we discuss our empirical specification. Section 5 presents our results. Section 6 concludes. Our bottom line is that conversions to for-profit hospitals are harmful to elderly RAND 2012 
patients, at least in the first two years following the conversion. The increase in mortality, albeit temporary, is a matter of concern, especially since this is difficult for outside private agents to monitor. This market failure suggests a role for public oversight of such transactions. We find no evidence that conversion to for-profit status increases Medicare payments per hospital stay.

\section{Background and conceptual framework}

- For-profit hospitals maximize profit. This is done by setting output, quality, inputs, and patient mix at levels that achieve this objective. In the product market for Medicare-covered services (32\% of hospital revenue in 1998, U.S. Department of Commerce, 2000), price does not vary by output or quality level. Rather, a fixed price for the hospital stay is set under the Prospective Payment System (PPS) for an admission based on the patient's Diagnosis-Related Group (DRG). The DRG, each with an associated weight, depends on how diagnoses, diagnosis modifiers, and procedures are coded. Because they are paid based on the DRG for the admission, hospitals have an incentive to record diagnoses in a manner that will result in a DRG with a higher weight (Carter, Newhouse, and Relles, 1990).

There is some empirical evidence, based on a study of coding practices for pneumonia, that for-profit hospitals have been particularly adept in upcoding DRGs (Silverman and Skinner, 2001). Medicare's payment system also gives hospitals an incentive to perform more-intensive treatments if the more-intensive care receives a higher price and is more profitable, for example, to provide surgery to Medicare beneficiaries with heart attacks (see, e.g., Cutler and McClellan, 1998).

For-profit hospitals may be more responsive to such financial incentives than those organized under the other ownership forms. When a hospital switches from public or private nonprofit to for-profit status, it seems plausible to observe some increase in Medicare payments per admission for these reasons.

The Medicare price under PPS does not depend on quality of care. Yet Medicare beneficiaries may eschew hospitals for which quality of care is perceived to be relatively low. To maximize profit, for-profit hospitals may seek to cut inputs affecting care that is not readily observable to patients or even to their referring physicians, at the same time investing in amenities, nice rooms, waiting areas, food, and some fancy equipment, all of which are readily observable. The not-so-observable part is "noncontractable quality" (Hart, Shleifer, and Vishny, 1997).

Although cuts in personnel levels following conversion are observable in principle, in practice it may be difficult to distinguish between cuts that enhance efficiency from those that detract from noncontractable quality. Even for a "hard" outcome such as mortality, deaths during the hospital stay or immediately following discharge are relatively easily attributed to the hospital to which the patient was admitted.

Longer-term mortality, which also reflects hospital input use, is harder to monitor. Thus, a profit-seeking hospital may not cut inputs that might increase in-hospital deaths within the hospital, such as nursing, but it might do less intensive testing; perform fewer therapies for which Medicare does not explicitly pay; and do less postdischarge planning at the time of discharge from the hospital, such as placing heart attack patients on beta blockers and aspirin at discharge (see, e.g., Canto et al., 2000).

For public and private nonprofit hospitals, the residual claimant is not nearly as well defined. Profits may accrue to a municipality or a state or may be kept internally. But in any case, there is no counterpart to the shareholder of the for-profit firm. Thus, there is less for the managers to gain from maximizing profit. Other goals, such as increasing noncontractable quality and provision of public goods, are likely to be relatively more important (see, e.g., Newhouse, 1970; Hansmann, 1980).

Conversion to for-profit status should lead to increases in profit-seeking strategies, such as upcoding and reductions in personnel, especially to the extent that such reductions primarily affect noncontractable quality. The reverse should occur when hospitals convert away from for-profit status. Because a manager of a public or private nonprofit hospital and/or his boss cannot fully 
appropriate the gains from cost-reducing innovations, such a manager would be less likely to cut cost that in turn might adversely affect hard-to-monitor quality.

\section{Data}

- The study sample was drawn from the National Long-Term Care Survey (NLTCS), which is a national panel study fielded in 1982, 1984, 1989, and 1994.' Overall, 35,845 Medicare beneficiaries were included in the dataset for at least some time during this period. NLTCS drew its sample from Medicare enrollment records for persons aged 65 and over. A brief screener interview containing questions about performance of such tasks as eating, bathing, doing one's laundry, and about personal characteristics was administered to all persons sampled. Based on responses to the screener, full interviews were administered to persons who had at least one limitation in an Activity of Daily Living (ADL) - bathing, walking across a room, etc.—or an Instrumental Activity of Daily Living (IADL)-doing laundry, balancing checkbook, etc.

Data on individual elderly persons from various waves of the NLTCS were merged with data from other sources: Medicare claims, including those from hospital inpatient, outpatient, and physician Part B, from 1984 through 1995; dates of death from Medicare enrollment records; hospital characteristics, including ownership and ownership conversions; and area characteristics for the NLTCS Primary Sampling Unit (PSU) in which the NTLCS respondent lived-a Standard Metropolitan Statistical Area for persons living in metropolitan areas and a county for residents of nonmetropolitan areas. Area characteristics came from the Area Resource File, a county-based data file maintained by the U.S. Bureau of Health Professions.

Of particular importance to this study is the data file on ownership conversions that we constructed. To construct this file, we first matched ownership and ownership changes by comparing information from the American Hospital Association's Annual Survey of Hospitals with information available from Medicare Cost Reports. When the two sources agreed, we took the information as valid. When the sources disagreed, we placed telephone calls to the hospitals to ascertain if and when the hospital changed ownership. A total of 259 hospitals were contacted. Since the Medicare Cost Report data only extended back to 1985, for 1984-1985 conversions we had to accept the American Hospital Association designations as valid.

Overall, 659 hospitals changed ownership between 1984 and 1995. Of these, 180 hospitals converted from government or private nonprofit to for-profit status, and 148 hospitals converted in the opposite direction. Changes between government and private nonprofit were the most common ownership change, but we did not evaluate effects of such changes in our analysis. Instead, hospitals that underwent these ownership changes were considered to be nonconverting hospitals in our analysis.

In the first part of our analysis, the observational unit was a Medicare beneficiary admitted to a hospital. The file we used consisted of 91,892 admissions occurring during 1984-1995 (not only in the years in which the NLTCS was administered to households). We imposed a screen that no one could be admitted to a hospital within a two-day period after discharge from a hospital, thus eliminating hospital transfers for the same episode. The resulting sample was 73,503 from 3,645 hospitals. ${ }^{2}$ Of these, 133 hospitals converted from government $(\mathrm{G})$ or private nonprofit $(\mathrm{N})$ to for-profit (F) status during 1984 to 1995. From these hospitals, we had 2,592 hospital admissions that occurred either before, during, or after a conversion. Of the 3,645 hospitals, 81 converted from $\mathrm{F}$ to $\mathrm{G}$ or $\mathrm{N}$ ownership. From these hospitals, we had 949 admissions from the before-, during-, or after-conversion periods.

In a second sample, we assessed changes in hospital finances, capacity, and input use preconversion versus postconversion using the hospital/year as the observational unit. The primary purpose of the hospital-level analysis was to help interpret the results for the changes in quality

${ }^{1}$ The NLTCS was also conducted in 1999. but it was not available in time for our study.

2 In an earlier version, we used a six-month screen rather than a two-day screen. Using a six-month screen. the marginal effects of ownership conversions were similar, but with some loss of statistical power.

6 RANI) 2(112. 
and payments. For the hospital analysis. we selected the same 3,645 hospitals included in the patient-level analysis, using data from the Medicare Cost Report public use file for 1985-1995. The mean number of observations per hospital was 10.2. A few hospitals merged or closed during this period, losing their hospital identifiers, and therefore could not be followed for the entire 11-year period.

\section{Empirical specification}

- Hospital quality and Medicare payments analysis. To measure survival following a hospital admission, we specified three dependent variables: death at 30 days, six months, and one year. When the dependent variable was binary, we used a linear probability model. For Medicare payments, the dependent variable was total Medicare payments for the admission, including payments to physicians (Part B payments). All monetarily expressed variables were converted to 1994 dollars using the Consumer Price Index, all items. The dependent variable for payments was transformed into natural log form.

Our analysis focused on the role of ownership conversions on quality and Medicare payments. To measure change in ownership, we first defined variables separately for conversions from $\mathrm{G}$ or $\mathrm{N}$ to $\mathrm{F}$ and for conversions from $\mathrm{F}$ to $\mathrm{G}$ or $\mathrm{N}$ status. For each of the two conversion types, we defined binary variables for these categories: admission was $5+$ years before the conversion (omitted reference group); 3-4 years before; 1-2 years before: admission during year of conversion; 1-2 years after; and $3+$ years after. For nonconverting hospitals, values of each of these binary variables were set to zero.

This approach allowed us to measure changes before as well as during and after conversion. Without including the preconversion binaries, one cannot exclude the possibility that care was worse after conversion than at nonconverting hospitals, but this was only a continuation of a trend in reduced quality of care that began well before the conversion occurred. Thus, without the preconversion binaries, we may have attributed quality decline to conversion, but this decline might have reflected other factors.

Other than hospital ownership conversion, explanatory variables fell into three categories: patient characteristics, market characteristics, and fixed effects. Patient characteristics were age at the date of the admission, gender, years of schooling completed, race (white versus nonwhite), being married, income, a binary variable for living in the community versus a nursing home. number of limitations in ADLs and IADLs, a binary variable for persons who were cognitively aware (answered seven or more questions correctly on a cognitive screen), and a binary variable for persons who lacked bowel and/or bladder control. Data for these variables were obtained from the NLTCS screener/interview before the admission. Thus, for example, if the admission year was 1991, we used values from the 1989 wave of NLTCS. In addition, we included a case-mix measure, the DxCG score for the admission. The DxCG classification system uses data on primary and secondary diagnoses, age, and gender from the discharge abstract (DxCG, 1996; Ellis et al.. 1996). In particular, the DxCG score contains diagnoses that were not the main reason for the admission but are likely to have had an important effect on the outcome.

We also included two explanatory variables for market characteristics: the wage index used by Medicare for setting payment rates at each hospital and population density-population per square mile. Both were defined for the patient's PSU. Year binary variables were included to account for technological change and other national changes in the health care system. We used hospital fixed effects to eliminate the correlation between the unmeasured heterogeneity (due to unmeasured severity of the shock) and the conversion dummy variables. Without the hospital fixed effects, least-squares estimates of conversion effects are possibly biased and inconsistent. ${ }^{3}$

${ }^{3}$ We did not use instrumental variables ( 1 ) because we would have had to measure determinants of a conversion. and (2) more important, because we lacked data on individual characteristics that could be excluded from the main equations. To preserve patient confidentiality, our data did not contain zip codes for patients; so we could not use differential distance as an IV.

(1) RAND 2002 
In our main specification, we used hospital fixed effects. Alternatively, we substituted area for hospital fixed effects. The area fixed effects were defined for the person's PSU at admission. There were 173 PSUs. Although hospital fixed effects are generally preferable, in preliminary analysis we found that we obtained more precise estimates of conversion effects with area fixed effects, since our dataset contained so many hospitals relative to the total number of admissions.

The PSU fixed effects analysis provides an important crosscheck on our hospital fixed effects analysis. In the analysis with PSU fixed effects, we included two additional explanatory variables to capture unmeasured heterogeneity of converting hospitals: a binary variable for hospitals that at some point converted from GN to $\mathrm{F}$, and a binary variable for hospitals that at some point converted from $\mathrm{F}$ to $\mathrm{GN}$. With the hospital fixed effects specification, the conversion fixed effects were incorporated in the individual hospital effects.

Finally, we included differential time trends by region (in addition to the year fixed effects) to account for regional time-varying changes that may have differentially affected converting and nonconverting hospitals. The region was defined as the Census Area in which the hospital was located. Interactions between time and hospital- or PSU-fixed effects were computationally infeasible.

$\square \quad$ Hospital-level analysis of finances, capacity, and staffing. The purpose of the hospitallevel analysis was to increase our understanding about why changes in quality and payments attributable to hospital ownership conversion occurred.

With the hospital as the observational unit, the dependent variables were operating margin, bed size, total employment, and total wages and salaries. The latter two dependent variables were expressed in levels and, alternatively, as ratios to hospital output. We measured output as the hospital's annual number of adjusted patient days. The adjustment accounts for the number of hospital outpatient visits. The dependent variables for bedsize, total employment, and wages and salaries were expressed in natural $\log$ form. ${ }^{4}$ For the operating margin, we limited the sample to hospital observations with margins of -.5 and higher (about $1 \%$ were below this value). Explanatory variables were the conversion binary variables, year binary variables, and hospital fixed effects.

$\square$ Analysis of patient mix. To assess whether or not our results on effects of hospital ownership conversions on quality could have been due to changes in unobserved severity of illness that are correlated with conversions, we assessed the effects of ownership changes on the DxCG score, the number of ADL limitations, and predicted mortality at one year. The observational unit for this analysis was the individual patient.

\section{Results}

Crude mortality rates. Without controlling for other factors, mortality rates increased following conversion from government or private nonprofit to for-profit status. By contrast, if anything, conversions from for-profit to either government or private nonprofit ownership led to decreased mortality (Table 1).

Among hospitals that eventually converted from $\mathrm{G}$ or $\mathrm{N}$ to $\mathrm{F}$ ownership, the mean mortality rate at 30 days following admission to the hospital was .075 for admissions occurring five or more years before conversion. This rate was fairly steady until $1-2$ years after conversion when the rate increased to .13. At three and more years after conversion, the rate was $.105, .03$ higher than at five or more years before the conversion occurred. Corresponding differentials between admissions occurring at five or more years before the conversion to those occurring three or more years after the conversion for six-month and one-year mortality were .07 and .08 , respectively. Overall, with some irregularities, the patterns for the other mortality categories, six months and one year after admission, were similar to that for 30 days - a marked increase in mortality through 1-2 years after conversion, followed by a decrease in the $3+$ years after the conversion period.

${ }^{4}$ In analysis not presented here, we also assessed effects of ownership conversion in the hospital's debt-to-assets ratio and in the hospital's occupancy rate. Results are available from the authors on request.

O RAND 2002. 


\begin{tabular}{|c|c|c|c|c|c|c|c|c|}
\hline & \multicolumn{4}{|c|}{ GN to $\mathrm{F}$} & \multicolumn{4}{|c|}{$F$ to $\mathrm{GN}$} \\
\hline & \multicolumn{3}{|c|}{ Mortality } & \multirow[b]{2}{*}{ Payments } & \multicolumn{3}{|c|}{ Mortality } & \multirow[b]{2}{*}{ Payments } \\
\hline & 1 Month & 6 Months & 1 Year & & 1 Month & 6 Months & I Year & \\
\hline $\begin{array}{l}5+\text { years before } \\
\text { convert }\end{array}$ & $\begin{array}{c}.0754 \\
(.0080) \\
{[-]}\end{array}$ & $\begin{array}{l}.1757 \\
(.0115) \\
--]\end{array}$ & $\begin{array}{c}.2484 \\
(.0345) \\
{[-]}\end{array}$ & $\begin{array}{c}7,211 \\
(337) \\
{[-]}\end{array}$ & $\begin{array}{l}.1031 \\
(.017) \\
{[-]}\end{array}$ & $\begin{array}{l}.2250 \\
(.0233) \\
{[-]}\end{array}$ & $\begin{array}{c}.2843 \\
(.0252) \\
{[-]}\end{array}$ & $\begin{array}{c}5.394 \\
(397) \\
1-1\end{array}$ \\
\hline $\begin{array}{l}\text { 3-4 years before } \\
\text { convert }\end{array}$ & $\begin{array}{c}.0828 \\
(.1142) \\
{[.6492]}\end{array}$ & $\begin{array}{c}.1978 \\
(.0206) \\
{[.3492]}\end{array}$ & $\begin{array}{l}.2941 \\
(.0235) \\
{[.0843]}\end{array}$ & $\begin{array}{r}9.105 \\
(692) \\
{[0142]}\end{array}$ & $\begin{array}{c}.0628 \\
(.0176) \\
{[.1006]}\end{array}$ & $\begin{array}{c}.1413 \\
(.0252) \\
{[.0155]}\end{array}$ & $\begin{array}{l}.1623 \\
(.0267) \\
{[.0010]}\end{array}$ & $\begin{array}{r}7,332 \\
(620) \\
{[.0089]}\end{array}$ \\
\hline $\begin{array}{l}\text { 1-2 years before } \\
\text { convert }\end{array}$ & $\begin{array}{c}.0683 \\
(.0121) \\
{[.3801]}\end{array}$ & $\begin{array}{l}.2080 \\
(.0203) \\
{[.1677]}\end{array}$ & $\begin{array}{l}.2656 \\
(.0221) \\
{[.4796]}\end{array}$ & $\begin{array}{r}8,379 \\
(494) \\
{[.0515]}\end{array}$ & $\begin{array}{c}.0875 \\
(.0224) \\
{[.5791]}\end{array}$ & $\begin{array}{c}.1687 \\
(.0297) \\
{[.1376]}\end{array}$ & $\begin{array}{l}.2562 \\
(.0346) \\
\lceil .5121]\end{array}$ & $\begin{array}{r}7.204 \\
(784) \\
{[.0409]}\end{array}$ \\
\hline Year of convert & $\begin{array}{c}.0828 \\
(.0220) \\
{[.7540]}\end{array}$ & $\begin{array}{c}.1910 \\
(.0314) \\
{[.6472]}\end{array}$ & $\begin{array}{l}.2484 \\
(.0345) \\
{[.9798]}\end{array}$ & $\begin{array}{c}9,789 \\
(1,129) \\
{[.0300]}\end{array}$ & $\begin{array}{c}.0769 \\
(.0333) \\
{[.4853]}\end{array}$ & $\begin{array}{c}.2000 \\
(.0500) \\
{[.6516]}\end{array}$ & $\begin{array}{l}.2615 \\
(.0549) \\
{[.7055]}\end{array}$ & $\begin{array}{r}7,513 \\
(1,033) \\
{[.0513]}\end{array}$ \\
\hline $\begin{array}{l}\text { 1-2 years after } \\
\text { convert }\end{array}$ & $\begin{array}{l}.1323 \\
(.0237) \\
{[.0242]}\end{array}$ & $\begin{array}{l}.2843 \\
(.0316) \\
{[.0014]}\end{array}$ & $\begin{array}{l}.3872 \\
(.0341) \\
{[.0002]}\end{array}$ & $\begin{array}{r}10,807 \\
(977) \\
{[.0006]}\end{array}$ & $\begin{array}{c}.1250 \\
(.0339\} \\
{[.5654]}\end{array}$ & $\begin{array}{c}.2083 \\
(.0416) \\
{[.7277]}\end{array}$ & $\begin{array}{l}.2187 \\
(.0424) \\
{[.1855]}\end{array}$ & $\begin{array}{r}7.486 \\
(975) \\
{[.0592]}\end{array}$ \\
\hline $\begin{array}{c}3+\text { years after } \\
\text { convert }\end{array}$ & $\begin{array}{c}.1051 \\
(.0159) \\
{[.0968]}\end{array}$ & $\begin{array}{l}.2506 \\
(.0225) \\
{[.0032]}\end{array}$ & $\begin{array}{c}.3315 \\
(.0244) \\
{[.0026]}\end{array}$ & $\begin{array}{r}11,040 \\
(610) \\
{[.0000]}\end{array}$ & $\begin{array}{c}.0854 \\
(.0259) \\
{[.5701]}\end{array}$ & $\begin{array}{c}.1452 \\
(.0327) \\
{[.0486]}\end{array}$ & $\begin{array}{c}.1794 \\
(.0356) \\
{[.0171]}\end{array}$ & $\begin{array}{r}8,039 \\
(822) \\
{[.0043]}\end{array}$ \\
\hline
\end{tabular}

Standard errors in parentheses and $p$ values of $t$ tests relative to $5+$ years before conversion in brackets.

For conversions from $\mathrm{F}$ to $\mathrm{GN}$ ownership, there was no corresponding increase in mortality after the conversion occurred. In fact, for six-month and one-year mortality, death rates for the $3+$ year postconversion period were lower than at $5+$ years before conversion. Thus, for hospitals converting away from for-profit ownership, it appears that quality of care improved following the ownership conversions.

$\square \quad$ Medicare payment per admission unadjusted for other covariates. Mean payments from Medicare per hospital stay increased monotonically from 5+ years before the conversion for the hospitals that converted from GN to F status and almost monotonically for those converting from $\mathrm{F}$ to GN (an exception being 1-2 years after conversion). There was a secular increase in real Medicare payments per stay, requiring multivariate analysis to sort out even approximate impacts of conversion on such payments.

$\square \quad$ Mortality and Medicare payments controlling for other covariates. In Table 2, we show complete results (less time, hospital fixed effects, and time-region interactions) for death at one year. Most of the effects on explanatory variables other than hospital ownership conversion have plausible and statistically significant relationships with the dependent variable. Results for the other patient-level analyses (not shown) are similar to Table 2's. The most significant predictor of mortality was a case-mix measure, the DxCG score. Older persons, males, less-educated persons, those who were not cognitively aware, had limitations in ADL and IADL, and/or had bowel or bladder incontinence at the NLTCS interview preceding the hospital admission had a higher probability of dying.

Holding other variables constant, including year and hospital fixed effects and regionalyear interactions, hospitals converting from $\mathrm{GN}$ to $\mathrm{F}$ status experienced higher rates of mortality (c) RAND 2002 


\section{$514 \quad /$ THE RAND JOURNAL OF ECONOMICS}

TABLE 2 Sample Means and Standard Deviations, and Full Results for One-Year Mortality

\begin{tabular}{|c|c|c|c|c|}
\hline & Mean & $\begin{array}{l}\text { Standard } \\
\text { Deviation }\end{array}$ & Coefficient & $\begin{array}{c}\text { Standard } \\
\text { Error }\end{array}$ \\
\hline \multicolumn{5}{|l|}{ Dependent Variables } \\
\hline \multicolumn{5}{|l|}{ Mortality } \\
\hline 1 month & .0923 & .2895 & & \\
\hline 6 months & .2046 & .4034 & & \\
\hline lyear & .2725 & .4452 & & \\
\hline Payments & 7,854 & 11,030 & & \\
\hline \multicolumn{5}{|l|}{ Explanatory Variables } \\
\hline \multicolumn{5}{|l|}{ GN to F: } \\
\hline $3-4$ years before convert & .0051 & .0711 & -.0012 & .0266 \\
\hline $1-2$ years before convert & .0054 & .0734 & -.0185 & .0266 \\
\hline Year of convert & .0021 & .0461 & -.0014 & .0372 \\
\hline $1-2$ years after convert & .0027 & .0526 & $.0924^{\mathrm{b}}$ & .0378 \\
\hline $3+$ years after convert & .0050 & .0708 & .0013 & .0365 \\
\hline Converting hospital fixed effect & & & .0353 & .1844 \\
\hline \multicolumn{5}{|l|}{ F to $\mathrm{GN}$ : } \\
\hline 3-4 years before convert & .0026 & .0509 & $-.1076^{\mathrm{a}}$ & .0408 \\
\hline $1-2$ years before convert & .0022 & .0466 & .0118 & .0424 \\
\hline Year of convert & .0009 & .0297 & -.0489 & .0609 \\
\hline $1-2$ years after convert & .0013 & .0398 & -.0744 & .0533 \\
\hline $3+$ years after convert & .0016 & .0398 & $-.1120^{\circ}$ & .0578 \\
\hline Converting hospital fixed effect & & & .0129 & .1128 \\
\hline \multicolumn{5}{|l|}{ Other Variables } \\
\hline Age & 77.39 & 8.55 & $.0058^{\mathrm{a}}$ & .0002 \\
\hline Male & .4115 & .4921 & $.0723^{\mathrm{a}}$ & .0035 \\
\hline Education & 9.685 & 2.525 & $-.0028^{\mathrm{a}}$ & .0007 \\
\hline White & .8858 & .3179 & $-.0097^{\mathrm{c}}$ & .0055 \\
\hline Married & .3874 & .4871 & $-.0317^{\mathrm{a}}$ & .0040 \\
\hline Income & 1.5071 & .9826 & $.0040^{c}$ & .0021 \\
\hline DxCG score & 1.4294 & 1.4706 & $.0852^{\mathrm{a}}$ & .0011 \\
\hline Lived in the community & .8171 & .3865 & $.1692^{\mathrm{a}}$ & .0138 \\
\hline ADLs & .8941 & 1.7054 & $.0212^{\mathrm{a}}$ & .0014 \\
\hline IADLs & .6152 & 1.636 & $.0308^{\mathrm{a}}$ & .0025 \\
\hline Cognitively : iware & .2166 & .4192 & $-.0366^{\mathrm{a}}$ & .0043 \\
\hline Bowel problems & .0406 & .1974 & $.0270^{\mathrm{a}}$ & .0082 \\
\hline Population density & .7662 & 1.039 & $.0204^{\mathrm{a}}$ & .0051 \\
\hline Wage index & .2623 & .0508 & $-.6705^{\mathrm{a}}$ & .0956 \\
\hline Constant & & & $-3242^{\mathrm{a}}$ & .0337 \\
\hline Number of observations & 73,503 & & & \\
\hline
\end{tabular}

Year fixed effects, hospital fixed effects, and time-trend-region interaction effects are included in the regression, but not shown in the table. The converting hospital fixed effects were included only in the analysis using area fixed effects.

a Significant at $1 \%$ level (two-tail test).

b Significant at $5 \%$ level (two-tail test)

c Significant at $10 \%$ level (two-tail test).

(1) RAND 2012. 


\begin{tabular}{|c|c|c|c|c|c|c|}
\hline & \multicolumn{3}{|c|}{ GN to $F$} & \multicolumn{3}{|c|}{$\mathrm{F}$ to $\mathrm{GN}$} \\
\hline & I Month & 6 Months & 1 Year & 1 Month & 6 Months & I Year \\
\hline \multicolumn{7}{|c|}{ Specification 1: Hospital Fixed Effects } \\
\hline $\begin{array}{l}\text { 3-4 years before } \\
\text { convert }\end{array}$ & $\begin{array}{r}-.0094 \\
(.0182)\end{array}$ & $\begin{array}{r}-.0143 \\
(.0243)\end{array}$ & $\begin{array}{r}-.0012 \\
(.0266)\end{array}$ & $\begin{array}{r}-.0437 \\
(.0279)\end{array}$ & $\begin{array}{r}-.0732^{\mathrm{c}} \\
(.0373)\end{array}$ & $\begin{array}{r}-.1076^{\mathrm{a}} \\
(.0408)\end{array}$ \\
\hline $\begin{array}{l}\text { 1-2 years before } \\
\text { convert }\end{array}$ & $\begin{array}{r}-.0339^{\circ} \\
(.0182)\end{array}$ & $\begin{array}{c}-.0150 \\
(.0244)\end{array}$ & $\begin{array}{r}-.0185 \\
(.0267)\end{array}$ & $\begin{array}{c}.0029 \\
(.0291)\end{array}$ & $\begin{array}{c}-.0143 \\
(.0389)\end{array}$ & $\begin{array}{l}.0118 \\
(.0424)\end{array}$ \\
\hline Year of convert & $\begin{array}{r}-.0081 \\
(.0255)\end{array}$ & $\begin{array}{r}-.0180 \\
(.0341)\end{array}$ & $\begin{array}{r}-.0014 \\
(.0372)\end{array}$ & $\begin{array}{r}-.0446 \\
(.0417)\end{array}$ & $\begin{array}{r}-.0581 \\
(.0557)\end{array}$ & $\begin{array}{r}-.0489 \\
(.0609)\end{array}$ \\
\hline $\begin{array}{l}\text { 1-2 years after } \\
\text { convert }\end{array}$ & $\begin{array}{c}.0310 \\
(.0259)\end{array}$ & $\begin{array}{c}.0514 \\
(.0346)\end{array}$ & $\begin{array}{c}.0925^{b} \\
(.0378)\end{array}$ & $\begin{array}{l}.0151 \\
(.0365)\end{array}$ & $\begin{array}{r}-.0214 \\
(.0488)\end{array}$ & $\begin{array}{r}-.0744 \\
(.0533)\end{array}$ \\
\hline $\begin{array}{l}3+\text { years } \\
\text { after convert }\end{array}$ & $\begin{array}{r}-.0178 \\
(.0250)\end{array}$ & $\begin{array}{r}-.0162 \\
(.0334)\end{array}$ & $\begin{array}{c}.0013 \\
(.0365)\end{array}$ & $\begin{array}{r}-.0167 \\
(.0396)\end{array}$ & $\begin{array}{r}-.0833 \\
(.0529)\end{array}$ & $\begin{array}{r}-.1120^{\circ} \\
(.0578)\end{array}$ \\
\hline \multicolumn{7}{|c|}{ Specification 2: PSU Fixed Effects and Hospital Conversion Fixed Effects } \\
\hline $\begin{array}{l}3-4 \text { years before } \\
\text { convert }\end{array}$ & $\begin{array}{r}-.0016 \\
(.0167)\end{array}$ & $\begin{array}{c}.0107 \\
(.0225)\end{array}$ & $\begin{array}{c}.0320 \\
(.0247)\end{array}$ & $\begin{array}{r}-.0277 \\
(.0253)\end{array}$ & $\begin{array}{r}-.0555 \\
(.0341)\end{array}$ & $\begin{array}{r}-.0833^{\mathrm{b}} \\
(.0374)\end{array}$ \\
\hline $\begin{array}{l}\text { 1-2 years before } \\
\text { convert }\end{array}$ & $\begin{array}{r}-.0232 \\
(.0163)\end{array}$ & $\begin{array}{c}.0176 \\
(.0220)\end{array}$ & $\begin{array}{c}-.0017 \\
(.0242)\end{array}$ & $\begin{array}{c}.0000 \\
(.0268)\end{array}$ & $\begin{array}{r}-.0256 \\
(.0361)\end{array}$ & $\begin{array}{l}.0086 \\
(.0396)\end{array}$ \\
\hline Year of convert & $\begin{array}{l}.0015 \\
(.0237)\end{array}$ & $\begin{array}{c}.0186 \\
(.0320)\end{array}$ & $\begin{array}{c}.0144 \\
(.0351)\end{array}$ & $\begin{array}{r}-.0318 \\
(.0377)\end{array}$ & $\begin{array}{r}-.0334 \\
(.0507)\end{array}$ & $\begin{array}{r}-.0301 \\
(.0557)\end{array}$ \\
\hline $\begin{array}{l}\text { 1-2 years after } \\
\text { convert }\end{array}$ & $\begin{array}{r}.0363^{c} \\
(.0212)\end{array}$ & $\begin{array}{c}.0849^{\mathrm{a}} \\
(.0286)\end{array}$ & $\begin{array}{c}.1173^{\mathrm{a}} \\
(.0314)\end{array}$ & $\begin{array}{c}.0220 \\
(.0323)\end{array}$ & $\begin{array}{r}-.0079 \\
(.0435)\end{array}$ & $\begin{array}{r}-.0402 \\
(.0478)\end{array}$ \\
\hline $\begin{array}{l}3+\text { years } \\
\text { after convert }\end{array}$ & $\begin{array}{l}.0063 \\
(.0173)\end{array}$ & $\begin{array}{l}.0458^{\mathrm{b}} \\
(.0233)\end{array}$ & $\begin{array}{l}.0522^{\mathrm{b}} \\
(.0256)\end{array}$ & $\begin{array}{r}-.0022 \\
(.0302)\end{array}$ & $\begin{array}{r}-.0505 \\
(.0407)\end{array}$ & $\begin{array}{r}-.0531 \\
(.0447)\end{array}$ \\
\hline $\begin{array}{l}\text { Converting hospital } \\
\text { fixed effect }\end{array}$ & $\begin{array}{r}-.0155^{c} \\
(.0088)\end{array}$ & $\begin{array}{r}-.0294^{b} \\
(.0118)\end{array}$ & $\begin{array}{r}-.0292^{b} \\
(.0130)\end{array}$ & $\begin{array}{l}.0071 \\
(.0158)\end{array}$ & $\begin{array}{c}.0122 \\
(.0213)\end{array}$ & $\begin{array}{r}-.0049 \\
(.0234)\end{array}$ \\
\hline
\end{tabular}

Standard errors in parentheses.

a Significant at $1 \%$ level (two-tail test).

${ }^{b}$ Significant at $5 \%$ level (two-tail test).

c Significant at $10 \%$ level (two-tail test).

following the conversion (Table 3 ). We begin with mortality at one year following admission to the hospital.

The probability of death at 1-2 years following conversion was .09 higher than it was $5+$ years before conversion, with the coefficient statistically significant at better than the $5 \%$ level. This is more than half of the differential in mortality implied by the crude mortality results in Table 1.

Before and through the year of conversion, the probability of dying at such hospitals was basically unchanged from the probability at $5+$ years before conversion. The increase in mortality after conversion was only temporary with the probability of dying $3+$ years after conversion being virtually the same as the probability $5+$ years before.

In the analysis of the probability of death at 30 days and at six months, the probability of death was also elevated at one to two years after conversion, but the differences between this rate and the reference group's were not statistically significant at conventional levels.

Overall, the results from the PSU fixed effects specification make an even stronger case that conversion to for-profit status leads to a reduction in quality. Like the results from the hospital (1) RAND 2002. 
fixed effects specification, the reduction in quality was highest in the period one to two years after the conversion, but in contrast to the earlier results, a reduction in quality remained in the $3+$ year postconversion period.

More specifically, in the specification using PSU fixed effects, the differential in mortality at one year following admission between the mortality rate at one to two years postconversion and the rate for five and more years prior to conversion was even larger than with hospital fixed effects, .12 versus .09 based on hospital fixed effects (and .14 using crude mortality rates). With area fixed effects, the coefficient on the binary for $3+$ years postconversion is statistically significant at better than the 5\% level, implying an increase in the probability of dying of .05 as compared with $5+$ years before conversion.

Although similar in magnitude to its counterpart based on the hospital fixed effects specification, the probability of death at 30 days was significantly higher at better than the $10 \%$ level for those patients admitted one to two years after conversion to for-profit ownership. In the analysis of mortality at six months, both the coefficients on the binary variables for 1-2 and 3+ years postconversion are statistically significant at better than the $5 \%$ level. The differences in mortality postconversion versus preconversion are considerable, .08 for $1-2$ years post versus $5+$ years pre and .05 for $3+$ years post versus $5+$ years pre. The negative coefficients on the converting hospital fixed effect in the PSU fixed effects specification imply that for-profit hospitals acquired higher-quality hospitals.

Results for the analysis of conversions from $F$ to GN status reveal a very different, but plausible, picture. There is no tendency to decreased quality following conversion. In fact, with hospital fixed effects, the probability of death at one year for those patients admitted to converting facilities $3+$ years after conversion was .11 lower than it was $5+$ years before conversion, a result statistically significant at better than the $10 \%$ level. In general, signs on the coefficients of the postconversion binary variables are negative, but statistical significance is lacking due to lack of statistical power. This result is not confirmed in the PSU-fixed effects analysis. In this analysis, the implication is that conversion away from for-profit status did not affect quality in either direction.

We found no effect of hospital ownership conversion in either direction on real Medicare payments per hospital stay, either for conversions to or away from for-profit status (Table 4). This conclusion holds for both the specification that includes hospital fixed effects as well as its counterpart using PSU fixed effects.

The DxCG score was highly significant in this analysis (not shown). To be sure that we did not overcorrect by including the DxCG score in the Medicare payment equations, we excluded this explanatory variable and reestimated the equation (not shown). For-profit hospitals may be more adept than others at manipulating diagnoses to raise Medicare payments, and the DxCG score is partly based on diagnoses. None of the postconversion parameter estimates were statistically significant at conventional levels. Clearly, if upcoding and other methods hospitals might use to obtain more money from Medicare are used disproportionately by for-profit hospitals, we are unable to detect this relationship.

$\square \quad$ Hospital-level analysis of finances, capacity, and staffing. As anticipated, converting from public or private nonprofit to for-profit ownership status led to an appreciable increase in hospital operating margins (Table 5, Panel A). Compared to 5+ years preconversion, margins fell up to the year in which the ownership conversion occurred. Margins rose during the conversion year and increased markedly thereafter, with the result that margins were .06 higher $3+$ years following conversion than they were $5+$ years before the conversion occurred.

The number of beds declined. At 3+ years postconversion, the number of beds per hospital was about $4 \%$ lower than at $5+$ years preconversion. Given the decline in quality, especially during the first two years following conversion from government or private nonprofit to for-profit status, the most important results in Panel A are for hospital employment. Hospital employment declined from $5+$ years before conversion with the peak decline occurring at $1-2$ years postconversion. Thereafter, employment rose slightly. The time path of employment changes coincides with the changes in quality for GN to F conversions documented above.

(1) RAND 2002 
TABLE $4 \quad$ Effects of Ownership Conversions on Medicare

Payments per Admission

\begin{tabular}{lcc}
\hline & GN to $F$ & $F$ to GN \\
\hline Specification 1: Hospital Fixed Effects & \\
$3-4$ years before convert & .1388 & $.3801^{\mathrm{b}}$ \\
& $(.1129)$ & $(.1785)$ \\
$1-2$ years before convert & $.1973^{\mathrm{c}}$ & .1249 \\
& $(.1133)$ & $(.1878)$ \\
Year of convert & .0783 & .1987 \\
& $(.1578)$ & $(.2625)$ \\
$1-2$ years after convert & -.0410 & -.1553 \\
& $(.1622)$ & $(.2292)$ \\
$3+$ years after convert & .1010 & .2195 \\
& $(.1553)$ & $(.2467)$
\end{tabular}

Specification 2: PSU Fixed Effects and Hospital Conversion Fixed Effects

\begin{tabular}{lcc}
$3-4$ years before convert & .0937 & .2299 \\
& $(.1055)$ & $(.1628)$ \\
$1-2$ years before convert & .1325 & -.0250 \\
& $(.1028)$ & $(.1757)$ \\
Year of convert & .0332 & -.0462 \\
& $(.1482)$ & $(.2386)$ \\
$1-2$ years after convert & .0603 & -.2953 \\
& $(.1348)$ & $(.2048)$ \\
$3+$ years after convert & .1373 & -.0401 \\
& $(.1075)$ & $(.1896)$ \\
Converting hospital fixed effect & -.0377 & -.04864 \\
& $(.0569)$ & $(.1053)$ \\
\hline
\end{tabular}

Standard errors in parenthesis.

${ }^{a}$ Significant at I\% level (two-tail test).

b Significant at $5 \%$ level (two-tail test).

"Significant at 10\% level (two-tail test).

The decline in employment may have been accompanied by a decline in output. Even adjusting for output, the drop in employment reached its maximum at 1-2 years postconversion.

Even more striking are the results for real wages and salaries to hospital employees. These fell dramatically during the conversion year - a rate of decline far exceeding that for employment, implying a reduction in hospital skill mix. There was some recovery afterward, with the percentage change in wages and salaries mirroring the percentage change in total employment. The pattern for wages and salaries per adjusted patient day is similar to the corresponding analysis of wages and salaries, a large decline during the conversion year followed by partial restoration of the cut in subsequent years.

Some of the above changes may have occurred with any ownership conversion, no matter what the direction; however, there are important differences in results for $G N$ to $F$ versus $F$ to GN conversions. For the latter, there was no increase in the operating margin after such conversions occurred. Total employment increased after conversion. The drop in wages and salaries during the conversion year was not nearly as great as for those hospitals converting to for-profit status. If anything, output-adjusted employment and wages and salaries increased postconversion.

O RAND 2002. 


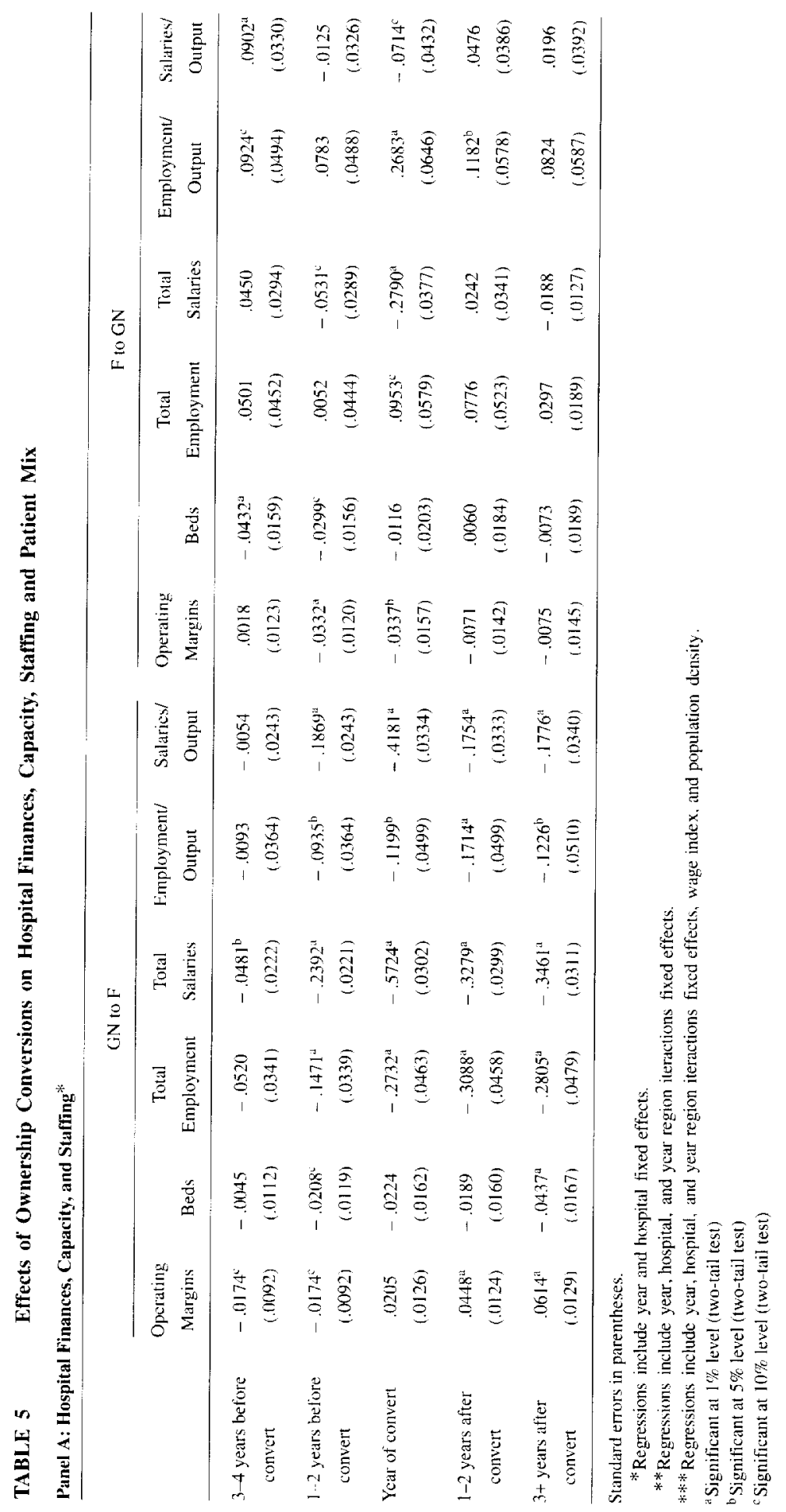




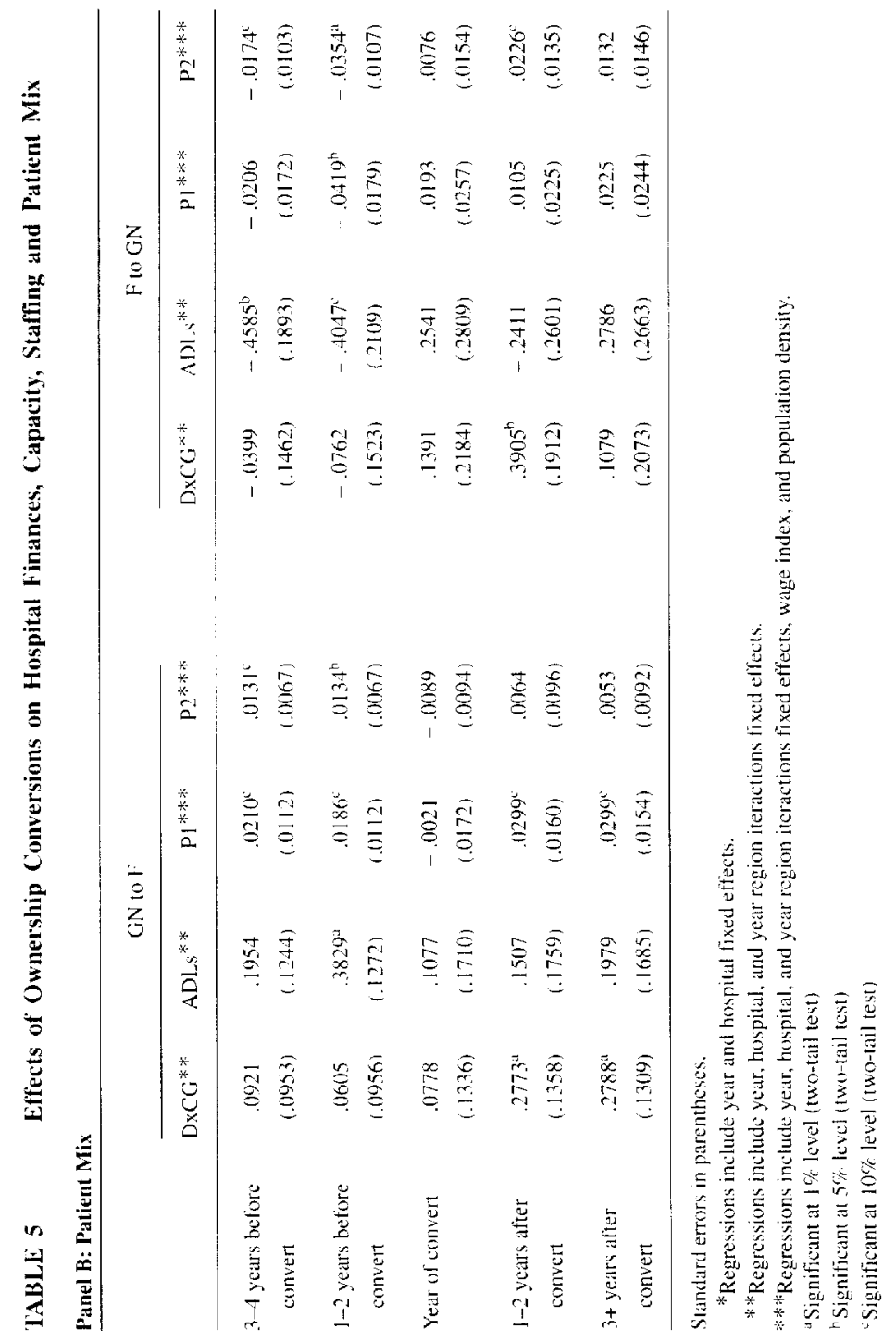


From these hospital-level results, the increase in mortality for hospitals converting from GN to F status, especially notable for the period 1-2 years after conversion, is possibly due at least in part to reductions in hospital employment, especially in highly skilled personnel. Once hospital leadership was able to observe the results of the cutbacks, it relented somewhat. with the consequence that mortality fell in the $3+$ year postconversion period from its $1-2$ year postconversion high.

$\sqsubset \quad$ Could the increase in mortality after conversion to for-profit ownership reflect unobserved severity of illness? An alternative explanation for the increase in mortality following conversion to for-profit status is that unobserved hospital case-mix severity increased. To study this issue further, we first analyzed observed hospital case-mix severity. This was accomplished by regressing the patient's DxCG score and number of ADL limitations at the NLTCS interview before the hospital stay on the conversion binary variables, hospital and year fixed effects, and region-time-trend interactions. The coefficients associated with the conversion dummy variables should capture the mean change in the patient mix after conversion. These results are presented in Panel B of Table 5.

The observable measures, DxCG and ADL, plausibly cannot measure all case-mix variation. Thus, we also analyzed more comprehensive measures of observed case-mix. Panel B also contains results with two patient-level predicted probabilities of one-year mortality as the dependent variables. The predicted probabilities reflect all of the patient-specific variables included in our mortality analysis (age, gender, race, etc.). The PI dependent variable was computed after switching all of the conversion binary variables to zero. All other explanatory variables (e.g.. wage index) were set to their sample mean values. Instead of allowing the DxCG score to vary among patients, $\mathrm{P} 2$ was computed by holding one patient-specific variable, the DxCG score, at its sample mean. Otherwise, the specification was the same as for the PI dependent variable.

As seen in Panel B, the DxCG score increased after conversion for patients admitted to hospitals converting from GN to F status. By contrast, we could find no statistically significant conversion effect for the mean number of ADL limitations. The case-mix measure PI increased postconversion. More specifically, it was .03 higher at $3+$ years postconversion than it was for admissions in the omitted reference group, admissions $5+$ years before the conversion to for-profit status occurred. In part, the result for PI reflects the substantial change in the DxCG score following hospital conversions to $F$ status. This could be due to some form of upcoding of diagnoses.

Eliminating the effect of the DxCG score (see P2 regression) for which upcoding may be a factor, the implied case-mix severity rose during the preconversion period from the $5+$ year before base. However, after conversion, severity of illness was no different from the $5+$ year omitted reference group.

For analysis of conversions from $\mathrm{F}$ to $\mathrm{GN}$ ownership, we also observed some increase in the DxCG score following conversion, but the change was most notable 1-2 years postconversion. The results for the number of ADLs revealed no clear pattern. For PI, the coefficient on the 3+ year postconversion binary variable was .02 , but not statistically significant at conventional levels. This coefficient was cut in half by eliminating the effect of DxCG (P2 column).

At first glance, some results from Panel B based on observed patient severity suggest that there may be some unobserved patient severity that may have confounded the mortality results in the GN to $\mathrm{F}$ case. But this tentative conclusion does not withstand further scrutiny. First, the change in the predicted probabilities is very small relative to the corresponding crude mortality rates. Second, most of the increase in observed severity is due to an increase in the DxCG score. Third, the time shape of the predicted probabilities does not mirror the time shape of changes in mortality. Fourth, if anything, the results for the predicted probabilities are similar for the GN to $\mathrm{F}$ and $\mathrm{F}$ to GN cases. By contrast, the results of hospital mortality are markedly different.

\section{Discussion and conclusions}

- Our analysis allowed us to assess effects of switching ownership, holding location constant. We found that converting from government or private nonprofit to for-profit ownership reduced RANT IMI: 
hospital quality, at least temporarily. There was no increase in real Medicare payments per stay attributable to hospital ownership conversions. Nor did we find a reduction in quality when hospitals switched from for-profit to government or private nonprofit ownership, implying that the result for the change in ownership toward for-profit status is not an artifact of converting, but rather of ownership status itself. As we emphasized above, it was necessary to distinguish between a quality reduction postconversion that was merely a continuation of a trend toward decreased quality already observed before the conversion from a switch to lower quality after conversion. Having made this distinction, the evidence points to a switch rather than a continuation of a trend.

Results are made stronger with evidence of a "smoking gun." Unfortunately, with administrative data, many guns are not observed. However, we did find a reduction in employment and wages-salaries at the time of conversion, which was partly reversed by the third year following conversion. One explanation is that the new management was initially charged with increasing hospital profitability. This was accomplished in large part by cutting labor inputs, especially highly skilled labor. Once the reduction in outcomes became apparent, management let up. This is a scenario of profit-seeking with learning.

An alternative interpretation is that conversion to for-profit status causes a shock to the hospital organization, which in turn increases mortality in the short run. Over time, the shock wears off. For the shock effect to operate and explain the observed patterns, it would be necessary for the shock to be much greater for conversions to than for those from for-profit status. Also, such shocks are not evident in case studies of hospital conversions (Anderson, Allred, and Sloan, 2001; Burns, Shah, and Sloan, 2001). There was no evidence of major disruptions at the hospitals following conversion. The case studies included conversions both toward and away from for-profit ownership.

Ideally, we would have been able to observe other indicators of hospital quality. Examples are aspirin and beta blocker use at discharge from the hospital following a heart attack (Chen et al., 1999).

Other studies based on the same data found no attenuation in effects of hospital characteristics on the probability of death, comparing 30 days postadmission versus one year postadmission (Peterson et al., 2000) or even for death at two years postadmission (Allison et al., 2000). In our analysis, we found stronger adverse effects for mortality for GN to F converting hospitals at one year than at earlier dates postadmission. Our analysis pertained to admissions for all diagnoses, not just for heart attacks.

Our failure to find a conversion to for-profit ownership effect for Medicare payments per hospital stay may suggest that upcoding, which Silverman and Skinner (2001) found for pneumonia, may not generalize to diagnoses overall. However, we did find a positive effect of converting to for-profit status on a case-mix measure based on primary and secondary diagnoses. This could reflect upcoding by for-profit hospitals designed to secure additional revenue from Medicare. One explanation for the difference in our results for Medicare payment and upcoding is that Medicare may have responded to upcoding by reducing its prices. Even if conversions to for-profit status are not harmful to Medicare in this respect, privately insured and uninsured patients may face price increases. We did not study the effect of ownership conversions on such prices.

What do these results mean for public policy? The mortality effects are somewhat troubling and may reflect massive changes at the hospital postconversion, including reductions in beds and in staffing (also see, e.g., Barro, 1998; Mark, 1999). Eventually hospital managers seemed to have learned from their mistakes, or staff simply adapted to the change to for-profit ownership. In the short run, market forces did not prevent excess mortality, suggesting a constructive role for public oversight of these transactions.

Previous studies have tended to show little or no difference in hospital behavior by ownership type, although the variation in financial incentives would certainly imply behavioral differences. Why might the previous studies have found no difference in spite of the strong theoretical prediction of differences?

One explanation is that past studies did not properly account for omitted heterogeneity. (4) RND 2012 
Another explanation is that competition among hospitals eliminates performance differences among hospitals with different ownership. Assuming that private nonprofit hospitals are more quality oriented than for-profit hospitals, the presence of a high nonprofit share in a market may force for-profit hospitals to maintain a higher quality level (Hansmann, 1980). New entry or changes in ownership of existing firms may cause the behavior of existing firms in the market to change until a new equilibrium is reached. This is known as a spillover effect.

Before a new equilibrium is established, there are at least two possibilities. In one, the existing firms wait until outcomes of the new entrant are observable, and only change if outcomes are favorable for the new entrant. A second possibility is that the behavior and success of the entrant is anticipated and the competitors adapt their behavior in advance of the move. If so, behavior of existing firms and entrants will be identical from the start.

We did not study the effect of spillovers of ownership changes on behavior of competing hospitals. A strong argument can be made for focusing on firm-specific effects of hospital conversions first. Assuming that firms in the market adopt the wait-and-see approach, if no firmspecific effect can be found even in the short run, it is really not possible to distinguish between no spillover and no effect of ownership incentives on behavior. While it is possible to deal with this problem by restricting the analysis to market areas with a single hospital, there are few such areas in which hospitals changed ownership. A useful extension of this study will be to examine spillovers.

\section{References}

Alıison, J.J.. Kiefe, C.I., Weissman, N.W., et al. "Relationship of Hospital Teaching Status with Quadity of Care and Mortality for Patients with Acute MI." Jommal of the American Medical Association. Vol. 284 (2000). pp. 1256-1262.

ANDirson, R.A.. AII.RID. C.A., ANI SIOAN, F.A. "Effect of Hospital Conversions on Organizational Decision Making and Service Coordination." Unpublished paper. 2001.

ARrow, K.I. "Uncertainty and the Welfare Economics of Medical Care." American Economic Reriew. Vol. 53 (1963), pp. $941-973$.

B.rRo, J.R. "Hospital Conversions to For-Profit Status: Causes and Consequences." Harvard University, November 1998.

Buris, L.R., SHAH, R., AND Siodn, F.A. "The Impact of Governance Changes on Strategy: Results from a Study of Hospital Ownership Conversions." Unpublished paper, 2001.

CANTo, J.G.. Every. N.R.. MAgin, D.J.. ET AL. "The Volume of Primary Angioplasty Procedures and Survival After Acute Myocardial Infarction." Nen England Joumal of Medicine. Vol. 342 (2000). pp. 1573-1580.

Carter, G.M., Newhouse, J.P., and Relles. D.A. "How Much Change in the Case Mix Index ]s Drg Creep?"” Journal of Heuthi Economics, Vol. 9 (1990), pp. $411-428$.

Cifin, J., Radforid, M.J., Wang, Y.. e.t Al. "Do America's Best Hospitals' Perform Better for Acute Myocardial Infarction'" New England Journal of Medicine, Vol. 340 (1999), pp. 286-292.

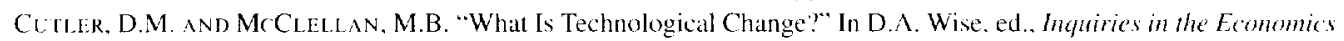
of Aging. Chicago: University of Chicago Press, 1998.

Desai. K.. Yolng. G.J., and Lukas. C.A. "Hospital Conversions from For-Profit to Nonprofit Status: The Other Side of the Story." Medical Care Research and Revien. Vol. 55 (1998), pp. 298-308.

DxCG, InC. DxCG Software Version:02e (Medicure) Program Documentation. Waltham, Mass.: DxCG, Inc.. 1996

Ea.I.IS. R.P., Pope, G.C., AND IEZzoni. L.I.. E1 AL. "Diagnosis-Based Risk Adjustment for Medicare Capitation Payments." Health Care Financing Review. Vol. 17 (1996), pp. 101-28.

Gowrisankakan. G. AND Town. R.J. "Estimating the Quality of Care in Hospitals Using Instrumental Variables." Joumal of Health Economics, Vol. 18 (1999), pp. 747-767.

Hansmann, II. "The Role of Nonprofit Enterprise." Yale Lan Journal, Vol. 89 (1980), pp. 835-901.

The Ownership of Enterprise. Cambridge, Mass.: Harvard University Press. 1996.

Hart, O.. Shr bifer, A., And Vishiy, R.W. "The Proper Scope of Government: Theory and an Application to Prisons." Quarterly Jounal of Economics. Vol. 112 (1997), pp. 1127-1162.

Hyman, D.A. "Hospital Conversions: Fact, Fantasy, and Regulatory Follies." Journal of Corporation Lan. Vol. 23 (1998). pp. $741-778$.

MARK. T.L. "Analysis of the Rationale for, and Consequences of, Nonprofit and For-Protit Ownership Conversions." Health Services Researh. Vol. 34 (1999), pp. 83-101.

Marstril.t.r, J., Bovbjerg. R.R., and Nichols, L.M. "Nonprofit Conversion: Theory. Evidence, and State Policy Options." Heulh Services Reseurch. Vol. 33 (1998), Part II, pp. 1495-1535.

CRAND $2(n) 2$ 
Mo Clellan, M. and Stalciter, D. "Comparing Hospital Quality at For-Profit and Not-for-Protit Hospitals." In D.M. Cutler, ed. The Changing Hospital Industry: Comparing Not-for-Profit and For-Profit Institutions. Chicago: University of Chicago Press. 2000, pp. 93-112.

Nifdleman, J.. Chol.tet, D.J.. And Lamphere. J. "Hospital Conversion Trends." Health Affuirs. Vol. 16 (1997). pp. $187-195$.

Newhouse, J.P. "Toward a Theory of Nonprofit Institutions: An Economic Model of a Hospital." American Econmic Review. Vol. 60 (1970), pp. 64-74.

Norton. E.C. and Staiger, D.O. "How Hospital Ownership Affects Access to Care for the Uninsured." RAND Jomal of Economics, Vol. 25 (1994). pp. 171-185.

Pfiterson, L.A.. NORMAnd, S.-L.T.. DALEY. J.. ani) M('Neil., B.J. "Oulcome of Myocardial Infarction in Veterans Health Administration Patients as Compared with Medicare Patients." New England Joumal of Medicine. Vol. 343 (2000). pp. 1934-1941.

Silvi:rman, E.M. and Skinner. J.S. "Are For-Profit Hospitals Really Different"? Medicare Upcoding and Market Structure." NBER Working Paper no. W8133, 2001.

Slodn, F.A. "Not-for-Profit Ownership and Hospital Behavior." In A.J. Culyer and J.P. Newhouse, eds., Handlook of Health Economics. Vol. 1B. New York: Elsevier. 2000.

. "Hospital Ownership Conversions: Detining the Appropriate Public Oversight Role." In A.M. Garber, ed. Frontiers in Health Policy Research. Cambridge. Mass.: MIT Press, 2002.

TAYlor, D.H., Whellan, D.J., AND SlonN. F.A. "Effects of Admission to a Teaching Hospital on the Cost and Quality of Care for Medicare Beneficiaries." New England Journal of Medicine, Vol. 340 (1999), pp. 293-299.

U.S. Department of Commerce. Statistical Abstract of the United States. Washington. D.C.: L.S. Government Printing Office. 2000.

WEIsBroD, B.A. The Nonprofit Economy: Cambridge. Mass.: Harvard University Press, 1988. 